Article

\title{
Evaluation of DFIGs' Primary Frequency Regulation Capability for Power Systems with High Penetration of Wind Power
}

\author{
Changgang Li ${ }^{1}$, Zhi Hang ${ }^{1}$, Hengxu Zhang ${ }^{1, * \mathbb{C}}$, Qi Guo ${ }^{2}$, Yihua Zhu ${ }^{2}$ and Vladimir Terzija ${ }^{1}$ \\ 1 Key Laboratory of Power System Intelligent Dispatch and Control of Ministry of Education, Shandong \\ University, Jinan 250061, China; lichgang@sdu.edu.cn (C.L.); hangzhi_sdu@163.com (Z.H.); \\ vladimir.terzija@yahoo.com (V.T.) \\ 2 Electric Power Research Institute, China Southern Power Grid, Guangzhou 510663, China; \\ guoqi@csg.cn (Q.G.); zhuyih@csg.cn (Y.Z.) \\ * Correspondence: zhanghx@sdu.edu.cn
}

Received: 16 October 2020; Accepted: 20 November 2020; Published: 24 November 2020

\begin{abstract}
Accompanying the continuous increase in wind power penetration, the power system inertia is reduced, and the system frequency regulation performance deteriorates. Wind turbine generators are required to participate in primary frequency regulation (PFR) to support system frequency. Here, the PFR capability of the widely-used doubly-fed induction generator (DFIG) is evaluated to estimate the participation of the DFIG in system frequency control. The frequency regulation model of the DFIG is established and briefly discussed. The equivalent PFR droop coefficient is then deduced from the model using a small signal increment method to evaluate the DFIG's PFR capability. Key factors affecting the equivalent droop coefficient are studied, and the droop control is optimized to keep the equivalent droop coefficient in the desired range. The proposed method is verified utilizing a provincial power grid model of China.
\end{abstract}

Keywords: doubly-fed induction generator; primary frequency regulation; equivalent droop coefficient; power systems

\section{Introduction}

The low-inertia renewable energy sources (RES) are developing rapidly. RES includes solar, wind, biomass energy and more. Among them, wind power generation is developing rapidly all over the world. The double-fed induction generator (DFIG) is the mainstream wind turbine generator type [1]. Regarding power systems with high wind power penetration, the system inertia is reduced since the rotor speed of the DFIG is decoupled from the system frequency [2,3]. Due to increasing wind power penetration, the influence of the system inertia reduction on the system frequency regulation becomes greater [4,5]. Therefore, DFIGs are required to participate in the system primary frequency regulation (PFR) in many countries [6,7].

Considering the literature, the primary methods for a DFIG to participate in frequency control are through virtual inertia control [8] and droop control [9]. Virtual inertia control responds to the rate of change of frequency (ROCOF). When the system frequency changes rapidly, the stored rotor kinetic energy (RKE) is released by the virtual inertia control to support the transient frequency $[10,11]$. The droop control adjusts the DFIG's active power command proportional to a system frequency deviation. The virtual inertia control and droop control make the DFIG participate in frequency regulation as in conventional generating units [12]. Since the spinning reserve is the prerequisite for DFIGs to participate in PFR, a DFIG is usually operated in over-speed mode $[13,14]$ or variable-pitch mode $[15,16]$ to achieve enough spinning reserve. 
The PFR capability is usually evaluated as the power generation change following the unit frequency change [17]. During the droop control, the active power command is generally the product of the frequency change and the droop control coefficient [18,19]. Therefore, in literature such as [20,21], the droop control coefficient is usually treated as the PFR capability of the DFIG. However, in many scenarios [22,23], the PFR capability of the DFIG is less than its droop control coefficient. It may lead to excessive estimation of system's PFR capability and a greater frequency deviation in power imbalance events.

When the DFIG's frequency regulation control changes the DFIG's active power output, the rotor speed of the wind turbines therefore is affected. To avoid significant rotor speed change, the DFIG is usually equipped with a rotor speed control and pitch angle control [24]. The changes of the rotor speed and pitch angle then affect the power absorbed from the wind. Therefore, the power generation corresponding to the unit frequency deviation is a joint result of the PFR control method, the model parameters, the operation mode, and the spinning reserve level. The droop control coefficient cannot accurately reflect the PRF capability of the DFIGs.

To estimate the PFR capability of the DFIGs, a small-signal increment method is adopted in this paper to derive the mathematical expression of the equivalent droop coefficient. The derivation is performed based on a typical PFR model of a DFIG. The equivalent droop coefficient is developed in over-speed and the variable-pitch modes have the droop control enabled. Key factors affecting the PFR capability of a DFIG also are studied. Furthermore, an optimized droop control coefficient is designed for different wind speeds to keep the equivalent droop coefficient in the desired range.

The rest of the paper is organized as follows. The PFR model of a DFIG is introduced in Section 2. The estimation method based on a small-signal increment method is proposed in Section 3. The influence of critical factors on the PFR capability of a DFIG is analyzed, and the droop control coefficient is optimized in Section 4. Some cases are studied in Section 5 to verify the proposed method, and conclusions are drawn in Section 6.

\section{DFIG Primary Frequency Regulation Model}

\subsection{The General Model of DFIG with Frequency Control}

Since the DFIG is decoupled from the system frequency, it cannot change the active power generation in response to the changes to the system frequency. The DFIG controls the electrical power output through the converter. When the power command of the converter is unchanged, the electrical power of the DFIG remains constant, and the DFIG does not participate in the primary frequency regulation.

To enable the DFIG to participate in the PFR, the power command of the converter is required to actively respond to the system frequency change with the electrical power control module. Since the input and output energy needs to be balanced to keep the DFIG in regular operation, the active change of electrical power generation requires the timely support of a mechanical power change from the wind turbine. When the mechanical power regulation cannot meet the changing electrical power demand, the DFIG has to release or absorb the RKE to meet the electrical power command. When the RKE changes significantly, the abnormal rotor speed may trigger speed protection logic, and the DFIG may be tripped. Therefore, to ensure continuous operation of the DFIG during participation in the PFR, the active power and mechanical power must be coordinated without aggressively releasing or absorbing the RKE.

The control for the active power and mechanical power can be found in the general DFIG model illustrated in Figure 1, where $f_{\text {meas }}, \omega, \omega_{\text {ref, }} \beta, \beta_{\text {ref }}, P_{\mathrm{m}}, P_{\mathrm{e}}, P_{\text {ord }}, V_{\mathrm{w}}, i_{\mathrm{p}}^{\text {ref }}$ are the measured frequency, the DFIG's rotor speed, the reference rotor speed, the pitch angle, the reference pitch angle, the mechanical power, the active power, the power order, the wind speed, and the reference active current, respectively. 


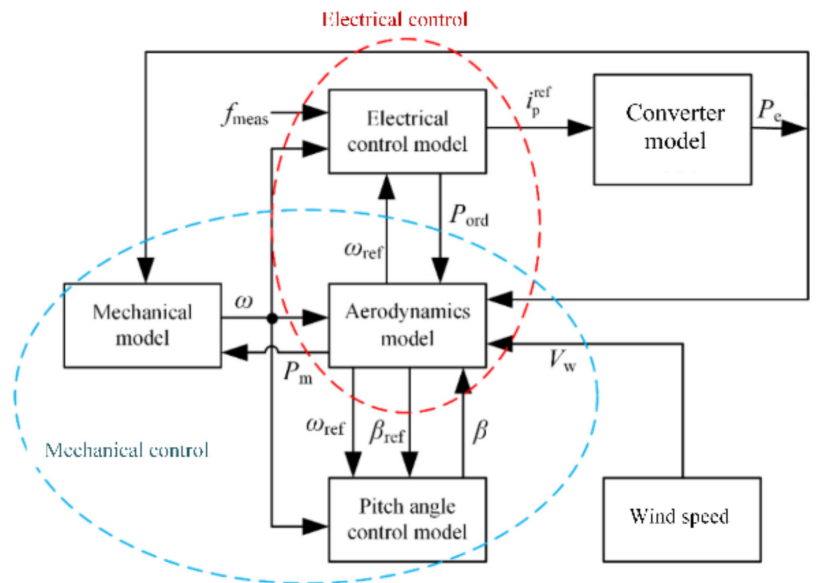

Figure 1. A general DFIG model contains five sub-models: a converter, an electrical control, aerodynamics, mechanical, and wind speed.

There are generally five sub-models in Figure 1: a converter model for generating power to the power grid, an electrical control model for adjusting active and reactive current command, an aerodynamics model for describing the aerodynamics of the wind turbine, the mechanical model for representing rotor dynamics, a pitch angle control model for adjusting pitch angle, and a wind model for mimicking wind speed change.

\subsection{Active Power Control}

Concerning the DFIG model, active power is controlled by the electrical control model [23]. It is implemented by adjusting $P_{\text {ord }}$ to respond to $f_{\text {meas }}$ and $\omega$. Figure 2 shows the diagram of a typical electrical control model, which comprises three control components: a virtual inertia control, a droop control, and a rotor speed control.

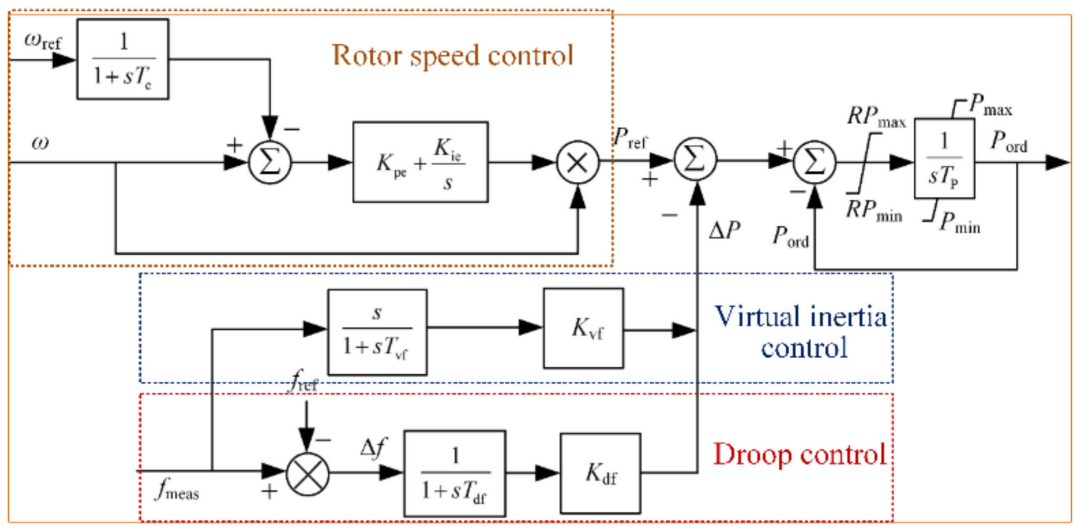

Figure 2. DFIG electrical control model contains a rotor speed control, a virtual inertia control, and a droop control.

Viewing Figure 2, $K_{\mathrm{pe}}$ and $K_{\mathrm{ie}}$ are, respectively, the ratio and differential coefficient of rotor speed control; $R P_{\max }$ and $R P_{\min }, P_{\max }$ and $P_{\min }$ are, respectively, the maximum and minimum rate of change to active power, the upper and lower limit of active power; $K_{\mathrm{vf}}$ and $K_{\mathrm{df}}$ are the virtual inertia control coefficient and the droop control coefficient; $T_{\mathrm{vf}}$ and $T_{\mathrm{df}}$ are the time constants of the virtual inertia control and the droop control; $T_{\mathrm{P}}$ and $T_{\mathrm{e}}$ are the time constants of the active power control and the rotor speed control; $f_{\text {ref }}$ and $\Delta f$ are the reference frequency and the variation of frequency in $\mathrm{Hz}$.

Regarding the electrical control model, the virtual inertia control and droop control are the two main parts responding to the frequency change. The virtual inertia control responds to the rate of 
change in frequency. When the system frequency changes rapidly, the stored rotor kinetic energy is released by the virtual inertia control to support the transient frequency. The droop control adjusts the DFIG's active power command proportional to a system frequency deviation. The virtual inertia control and droop control make the DFIG participate in frequency regulation as in conventional generating units. They are a proportional-differential (PD) controller. When the system reaches a new steady-state, the output of the virtual inertia control is 0 , and the change of the total frequency control command $\Delta P$ is:

$$
\Delta P=K_{\mathrm{df}} \Delta f
$$

The rotor speed control block in the electrical control model is used to adjust the turbine speed to follow $\omega_{\text {ref. }}$. When the DFIG releases or absorbs excessive RKE, the turbine speed deviates from the reference speed, and the rotor speed control block then adjusts the active power reference $P_{\text {ref }}$ to bring the rotor speed back. When the system reaches a new steady-state, the rotor speed is identical to $\omega_{\text {ref, }}$ and the change in the total speed control command $\Delta P_{\text {ref }}$ is:

$$
\Delta P_{\text {ref }}=K_{\text {ie }}\left(\omega_{0}+\Delta \omega_{\mathrm{s}}\right) \int_{0}^{\infty}\left(\Delta \omega-\Delta \omega_{\text {ref }}^{\mathrm{e}}\right) d t+T_{0} \Delta \omega_{\mathrm{s}}
$$

where $\omega_{0}, \Delta \omega_{\mathrm{s}}, \Delta \omega, \Delta \omega_{\text {ref }}^{\mathrm{e}}$ and $T_{0}$ are the initial rotor speed, a variation of rotor speed in steady-state, the variation of rotor speed, the actual perceived reference speed of the rotor speed control, and the initial torque, respectively.

Therefore, the change in total active power command is Equation (3) when the system reaches a new steady state.

$$
\Delta P_{\text {ord }}=-K_{\mathrm{df}} \Delta f+K_{\mathrm{ie}}\left(\omega_{0}+\Delta \omega_{\mathrm{s}}\right) \int_{0}^{\infty}\left(\Delta \omega-\Delta \omega_{\mathrm{ref}}^{\mathrm{e}}\right) d t+T_{0} \Delta \omega_{\mathrm{s}}
$$

\subsection{Mechanical Power Control Model}

The mechanical power of the DFIG is calculated by the aerodynamics model using $\omega$ from the mechanical model, $\beta$ from the pitch angle control model, and $V_{\mathrm{w}}$ from the wind model. Assuming wind speed is constant, the change in mechanical power can be derived from the pitch angle control model and the aerodynamics model [24].

The pitch angle control model is typically designed to control the rotor speed by adjusting the pitch angle and, therefore, the turbine mechanical power. Pitch angle control models also contain rotor speed control. Considering the pitch angle control model, the pitch angle signal is generated according to $\omega$ and $\omega_{\text {ref. }}$. Mechanical power depends on the variation of the pitch angle when the wind speed is fixed. The rotor speed control in the pitch angle control model, in other words, mainly affects the mechanical power. The pitch angle control model is shown in Figure 3 where $K_{\mathrm{pp}}$ and $K_{\mathrm{ip}}$ are, respectively, the ratio and differential coefficient in the pitch angle control; $R \beta_{\max }$ and $R \beta_{\min }, \beta_{\max }$ and $\beta_{\min }$ are, respectively, the maximum and minimum change rates of the pitch angle and the maximum and minimum pitch angle values.

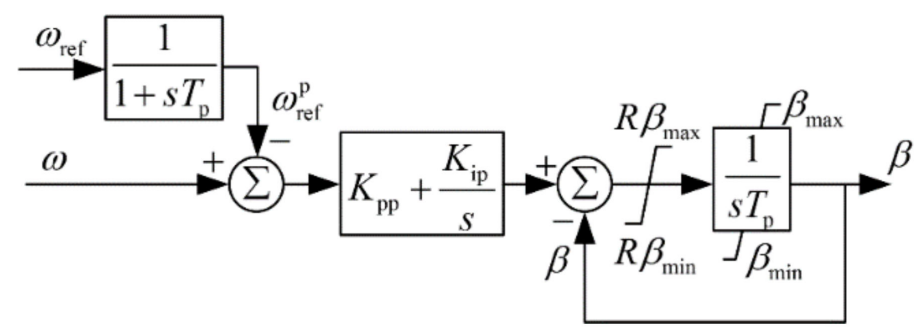

Figure 3. DFIG pitch angle control model for adjusting pitch angle. 
Viewing the DFIG model, the aerodynamics model is used for two purposes: calculation of mechanical power absorbed by the WTGs' impeller based on the rotor speed and pitch angle, and calculation of the reference speed signal based on the given power order and pitch angle. The relationship between the turbine mechanical power and the input of $\omega$ and $\beta$ is nonlinear, and the generally used approximation is [25]:

$$
\left\{\begin{array}{l}
P_{\mathrm{m}}=0.5 \rho \pi R^{2} C_{\mathrm{p}} V_{\mathrm{w}}^{3} \\
C_{\mathrm{p}}(\lambda, \beta)=c_{1}\left(\frac{c_{2}}{\lambda_{\mathrm{i}}}-c_{3} \beta-c_{4}\right) e^{-\frac{c_{5}}{\lambda_{\mathrm{i}}}}+c_{6} \lambda \\
\frac{1}{\lambda_{\mathrm{i}}}=\frac{1}{\lambda+c_{7} \beta}-\frac{c_{8}}{\beta^{3}+1} \\
\lambda=\frac{\omega \omega_{\text {base }} R}{V_{\mathrm{w}}}, \omega_{\text {base }}=\frac{2 \pi f_{\mathrm{N}}}{G p}
\end{array}\right.
$$

where $\lambda$ is the tip speed ratio, $\beta$ is the pitch angle, $R$ is the blade radius of the wind turbine, $\rho$ is the air density, $V_{\mathrm{W}}$ is the wind speed, $\lambda_{\mathrm{i}}$ is the intermediate variable in the formula simplification, and $C_{\mathrm{p}}(\lambda, \beta)$ is the wind energy conversion efficiency coefficient of the wind turbine.

\section{Equivalent PFR Droop Coefficient of DFIG}

Regarding a conventional unit, its PFR capability can be represented by the unit regulation power $\left(K_{\mathrm{G}}\right)$, the slope of the static frequency characteristic curve. Similarly, the unit regulation power of the DFIG is adopted in this paper to evaluate the PFR capability of DFIGs. The unit regulation power also is called the equivalent droop coefficient in this paper and is denoted as $K_{\mathrm{DFIG}}$ :

$$
K_{\text {DFIG }}=-\frac{\Delta P_{\mathrm{e}}}{\Delta f}=-\frac{\Delta P_{\text {ord }}}{\Delta f}
$$

Concerning a wind farm with $n$ DFIG WTGs, its total PFR capability is $K_{\Sigma}$ defined as:

$$
K_{\Sigma}=\sum_{j=1}^{n} K_{\mathrm{DFIG}, j}
$$

\subsection{Approximation of Active Power Change}

Based on the primary frequency regulation model of a DFIG, the active power of a DFIG varies according to the system frequency. When the system frequency changes, the electrical power variation of the DFIG can be expressed as:

$$
\begin{aligned}
\Delta P_{\mathrm{e}}^{*} & =\frac{\Delta P_{\mathrm{e}}}{S_{\mathrm{N}}}=P^{*}-P_{0}^{*} \\
& =-K_{\mathrm{df}} \Delta f^{*}+K_{\mathrm{ie}}\left(\omega_{0}^{*}+\Delta \omega_{\mathrm{s}}^{*}\right) \int_{0}^{\infty}\left(\Delta \omega^{*}-\Delta \omega_{\mathrm{ref}}^{\mathrm{e}}\right) d t+T_{0}^{*} \Delta \omega_{\mathrm{s}}^{*}
\end{aligned}
$$

where $K_{\mathrm{df}}{ }^{*}, \Delta f^{*}, \omega_{0}{ }^{*}, \Delta \omega_{\mathrm{s}}{ }^{*}, \Delta \omega_{\text {ref }}^{\mathrm{e}}, T_{0}{ }^{*}$ are the droop control coefficient, the variation of frequency, the initial rotor speed, the variation of the rotor speed in steady-state, the actual perceived reference speed of the rotor speed control, and the initial torque, respectively. The asterisk on a variable indicates that the variable is a per-unit value.

\subsubsection{Dynamic Response of Rotor Speed Control}

Concerning the electrical control model, the reference rotor speed is applied to the model after a delay $\left(T_{\mathrm{e}}\right)$. The perceived reference speed of the rotor speed control is $\omega_{\text {ref }}^{\mathrm{e}}{ }^{*}$, which meets:

$$
\frac{d \Delta \omega_{\mathrm{ref}}^{\mathrm{e}}}{d t}=\frac{1}{T_{\mathrm{e}}}\left[\Delta \omega_{\mathrm{ref}}^{*}(t)-\Delta \omega_{\mathrm{ref}}^{\mathrm{e}} *(t)\right]
$$


Integrating on both sides from zero to positive infinity:

$$
\int_{0}^{\infty} \Delta \omega_{\mathrm{ref}}^{\mathrm{e}}{ }^{*}(t) d t=\int_{0}^{\infty} \Delta \omega_{\mathrm{ref}}^{*}(t) d t-T_{\mathrm{e}} \Delta \omega_{\mathrm{s}}^{*}
$$

\subsubsection{Dynamic Response of Pitch Angle Control}

Regarding the pitch angle control model, the reference rotor speed is applied to the model after a time delay $\left(T_{\mathrm{p}}\right)$. The actual perceived reference speed of the rotor speed control is $\omega_{\text {ref }}^{\mathrm{p}}$, which meets:

$$
\frac{d \Delta \omega_{\mathrm{ref}}^{\mathrm{p}}}{d t}=\frac{1}{T_{\mathrm{p}}}\left[\Delta \omega_{\text {ref }}^{*}(t)-\Delta \omega_{\mathrm{ref}}^{\mathrm{p} *}(t)\right]
$$

Integrating on both sides from zero to positive infinity:

$$
\int_{0}^{\infty} \Delta \omega_{\mathrm{ref}}^{\mathrm{p}}(t) d t=\int_{0}^{\infty} \Delta \omega_{\mathrm{ref}}^{*}(t) d t-T_{\mathrm{p}} \Delta \omega_{\mathrm{s}}^{*}
$$

When the system frequency changes, a variation of the pitch angle in the steady-state is $\Delta \beta_{\mathrm{s}}$.

$$
\begin{aligned}
\Delta \beta_{\mathrm{s}} & =K_{\mathrm{ip}} \int_{0}^{\infty}\left(\Delta \omega^{*}-\Delta \omega_{\mathrm{ref}}^{\mathrm{p}}\right) d t \\
& =K_{\mathrm{ip}} T_{\mathrm{p}} \Delta \omega_{\mathrm{s}}^{*}+K_{\mathrm{ip}} \int_{0}^{\infty}\left(\Delta \omega^{*}-\Delta \omega_{\text {ref }}^{*}\right) d t
\end{aligned}
$$

The integral term can be expressed as,

$$
\int_{0}^{\infty}\left(\Delta \omega^{*}-\Delta \omega_{\text {ref }}^{*}\right) d t=\frac{\Delta \beta_{\mathrm{s}}}{K_{\mathrm{ip}}}-T_{\mathrm{p}} \Delta \omega_{\mathrm{s}}^{*}
$$

\subsubsection{Transform of Integral Terms}

Using Equations (9) and (13), the integral term generated by the torque change in Equation (14) can be transformed into:

$$
\int_{0}^{\infty}\left(\Delta \omega^{*}-\Delta \omega_{\text {ref }}^{\mathrm{e}}\right) d t=\frac{\Delta \beta_{\mathrm{s}}}{K_{\mathrm{ip}}}+\left(T_{\mathrm{e}}-T_{\mathrm{p}}\right) \Delta \omega_{\mathrm{s}}^{*}
$$

Substituting Equation (14) into Equation (7), the electrical power variation of the DFIG can be expressed as:

$$
\Delta P_{\mathrm{e}}^{*}=-K_{\mathrm{df}}^{*} \Delta f^{*}+K_{\mathrm{ie}}\left(\omega_{0}^{*}+\Delta \omega_{\mathrm{s}}^{*}\right)\left[\frac{\Delta \beta_{\mathrm{s}}}{K_{\mathrm{ip}}}+\left(T_{\mathrm{e}}-T_{\mathrm{p}}\right) \Delta \omega_{\mathrm{s}}^{*}\right]+\frac{P_{0}^{*}}{\omega_{0}^{*}} \Delta \omega_{\mathrm{s}}^{*}
$$

The second-order components are too small and can be neglected. Thus, Equation (15) can be simplified as:

$$
\Delta P_{\mathrm{e}}^{*} \approx-K_{\mathrm{df}}^{*} \Delta f^{*}+K_{\mathrm{ie}} \omega_{0}^{*}\left[\frac{\Delta \beta_{\mathrm{s}}}{K_{\mathrm{ip}}}+\left(T_{\mathrm{e}}-T_{\mathrm{p}}\right) \Delta \omega_{\mathrm{s}}^{*}\right]+\frac{P_{0}^{*}}{\omega_{0}^{*}} \Delta \omega_{\mathrm{s}}^{*}
$$

\subsection{Approximation of Mechanical Power}

Taken from Equation (4), it can be drawn that the mechanical power is affected by the rotor speed control and the pitch angle control. Thus, mechanical power can be linearized as a sum of rotor speed deviation and pitch angle deviation:

$$
\begin{aligned}
\Delta P_{\mathrm{m}} & =P_{\text {wind }} \Delta C_{\mathrm{p}}(\lambda, \beta)=P_{\text {wind }} \Delta C_{\mathrm{p} \omega}\left(\omega^{*}, \beta\right) \\
& =P_{\text {wind }} \frac{\partial C_{\mathrm{p} \omega}}{\partial \omega^{*}} \Delta \omega^{*}+P_{\text {wind }} \frac{\partial C_{\mathrm{p} \omega}}{\partial \beta} \Delta \beta
\end{aligned}
$$


where

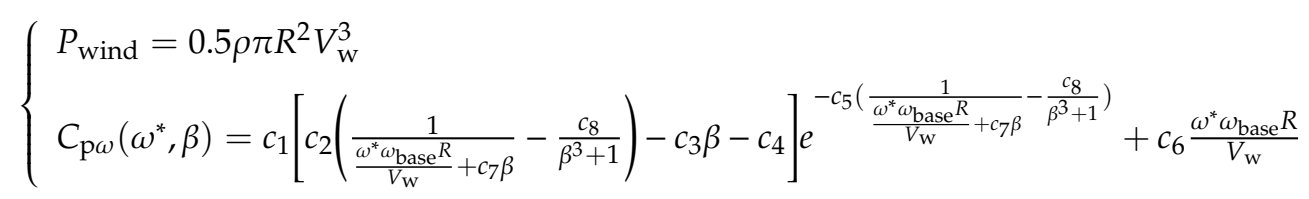

When $V_{\mathrm{w}}$ and the load shedding ratio (d) are fixed, the DFIG steady operating point will be expressed with the initial rotor speed $\omega_{0}$ and the initial pitch angle $\beta_{0}$.

$$
\left\{\begin{array}{l}
P_{\mathrm{MPPT}}=0.5 \rho \pi R^{2} C_{\mathrm{p} \omega}\left(\omega_{\mathrm{MPPT}^{*}}, \beta_{0}\right) V_{\mathrm{W}}^{3} \\
P_{\text {ord }}=(1-d \%) P_{\mathrm{MPPT}} \\
P_{\text {ord }}=0.5 \rho \pi R^{2} C_{\mathrm{p} \omega}\left(\omega_{0}{ }^{*}, \beta_{0}\right) V_{\mathrm{W}}^{3}
\end{array}\right.
$$

The change to the mechanical power in terms of $\Delta \omega_{0}$ and $\Delta \beta_{0}$ at the initial operating point $\left(\omega_{0}, \beta_{0}\right)$, can be expressed as:

$$
\begin{gathered}
\left.\Delta P_{\mathrm{m}}\right|_{\left(\omega_{0}{ }^{*}, \beta_{0}\right)}=P_{\text {wind }} \frac{\partial C_{\mathrm{p} \omega}}{\partial \omega^{*}} \Delta \omega^{*}+P_{\text {wind }} \frac{\partial C_{\mathrm{p} \omega}}{\partial \beta} \Delta \beta \\
\Delta P_{\mathrm{e}}{ }^{*}=\frac{\Delta P_{\mathrm{e}}}{S_{N}}=\frac{\Delta P_{\mathrm{m}}}{S_{N}}=\Delta P_{\mathrm{m}}{ }^{*}=P_{\partial \omega}{ }^{*} \Delta \omega^{*}+P_{\partial \beta}{ }^{*} \Delta \beta
\end{gathered}
$$

where

$$
\left\{\begin{array}{l}
P_{\partial \omega^{*}}{ }^{*}=\left.\frac{P_{\mathrm{wind}}}{S_{N}} \frac{\partial C_{\mathrm{p} \omega}}{\partial \omega^{*}}\right|_{\left(\omega_{0}^{*}, \beta_{0}\right)} \\
P_{\partial \beta^{*}}=\left.\frac{P_{\mathrm{wind}}}{S_{N}} \frac{\partial C_{\mathrm{p} \omega}}{\partial \beta}\right|_{\left(\omega_{0}^{*}, \beta_{0}\right)}
\end{array}\right.
$$

When the wind speed or $d$ changes, $\beta_{0}$ and $\omega_{0}$ will vary accordingly. Also, the PFR capability of the DFIG will be different.

\subsection{Equivalent PFR Droop Coefficient in Fixed-Pitch Angle Mode}

The DFIG steady-state operating point changes according to different wind speeds. Occurring at a low wind speed, the power reserve and regulation are achieved by changing the rotor speed. The pitch angle may change slightly during the transient process. However, the pitch angle will remain an initial value once a new steady state is reached. Therefore, the DFIG is operated in a fixed-pitch angle mode.

During the fixed-pitch angle mode, $\Delta \beta_{\mathrm{s}}=0$. Substituting it into Equation (16) gives,

$$
\left\{\begin{array}{l}
\Delta P_{\mathrm{e}}^{*}=-K_{\mathrm{df}}^{*} \Delta f^{*}+K_{\mathrm{ie}} \omega_{0}^{*}\left(T_{\mathrm{e}}-T_{\mathrm{p}}\right) \Delta \omega_{\mathrm{s}}^{*}+\frac{P_{0}^{*}}{\omega_{0}^{*}} \Delta \omega_{\mathrm{s}}^{*} \\
\Delta P_{\mathrm{m}}^{*}=P_{\partial \omega^{*}} \Delta \omega^{*}
\end{array}\right.
$$

$\Delta P_{\mathrm{e}}$ and $\Delta \omega_{\mathrm{s}}$ can be solved as:

$$
\begin{gathered}
\Delta P_{\mathrm{e}}{ }^{*}=\frac{P_{\partial \omega^{*}} K_{\mathrm{df}}{ }^{*}}{K_{\mathrm{ie}} \omega_{0}{ }^{*}\left(T_{\mathrm{e}}-T_{\mathrm{p}}\right)+\frac{P_{0}{ }^{*}}{\omega_{0}{ }^{*}}-P_{\partial \omega^{*}}{ }^{*}} \Delta f^{*} \\
\Delta \omega_{\mathrm{s}}=\frac{K_{\mathrm{df}}{ }^{*}}{K_{\mathrm{ie}} \omega_{0}{ }^{*}\left(T_{\mathrm{e}}-T_{\mathrm{p}}\right)+\frac{P_{0}{ }^{*}}{\omega_{0}{ }^{*}}-P_{\partial \omega^{*}}} \Delta f
\end{gathered}
$$

Since $P_{\partial \beta}{ }^{*}$ mainly depends on the partial derivative of $C_{\mathrm{p}}$ over $\beta$ and $\Delta \beta_{\mathrm{s}}=0, P_{\partial \beta}{ }^{*}$ is not included in Equations (24) and (25). 


\subsection{Equivalent PFR Droop Coefficient in Fixed-Rotor Speed Mode}

The DFIG steady-state operating point changes according to different wind speeds. Occurring at a high wind speed, the speed of the maximum power point (MPP) is close to the speed upper limit. Even if the fixing speed reaches the upper limit, the power reserve cannot be fully realized. The matching pitch angle control is required at this time. The DFIG is operated in a fixed-rotor speed mode in this condition.

During the fixed-rotor speed mode, $\Delta \omega_{\mathrm{s}}=0$. Equation (16) can be converted into,

$$
\left\{\begin{array}{l}
\Delta P_{\mathrm{e}^{*}}=-K_{\mathrm{df}}^{*} \Delta f^{*}+K_{\mathrm{ie}} \omega_{0} * \frac{\Delta \beta_{\mathrm{s}}}{K_{\mathrm{ip}}} \\
\Delta P_{\mathrm{m}}^{*}=P_{\partial \beta^{*}} \Delta \beta
\end{array}\right.
$$

$\Delta P_{\mathrm{e}}$ and $\Delta \beta_{\mathrm{s}}$ can be solved as:

$$
\begin{gathered}
\Delta P_{\mathrm{e}}^{*}=\frac{P_{\partial \beta^{*}} K_{\mathrm{df}}{ }^{*}}{\frac{K_{\mathrm{ie}} \omega_{0}^{*}}{K_{\mathrm{ip}}}-P_{\partial \beta^{*}}} \Delta f^{*} \\
\Delta \beta_{\mathrm{s}}=\frac{K_{\mathrm{df}}{ }^{*}}{\frac{K_{\mathrm{ie}} \omega_{0}{ }^{*}}{K_{\mathrm{ip}}}-P_{\partial \beta^{*}}} \Delta f^{*}
\end{gathered}
$$

Since $P_{\partial \omega}{ }^{*}$ mainly depends on the partial derivative of $C_{\mathrm{p}}$ over $\omega$ and $\Delta \omega_{\mathrm{s}}=0, P_{\partial \omega}{ }^{*}$ is not included in Equations (27) and (28).

Using previous analysis, the $K_{\mathrm{DFIG}}{ }^{*}$ in different operation modes is calculated in Equation (29).

$$
K_{\mathrm{DFIG}}^{*}=\left\{\begin{array}{l}
\frac{-P_{\partial \omega^{*}} K_{\mathrm{df}}{ }^{*}}{K_{\mathrm{ie}} \omega_{0}{ }^{*}\left(T_{\mathrm{e}}-T_{\mathrm{p}}\right)+\frac{P_{0}{ }^{*}}{\omega_{0}{ }^{*}}-P_{\partial \omega^{*}}{ }^{*}}, \text { fixed pitch angle mode } \\
\frac{-P_{\partial \beta^{*}{ }^{*} K_{\mathrm{df}}}}{\frac{K_{\mathrm{i}} \omega_{0}^{*}{ }^{*}}{K_{\mathrm{ip}}}-P_{\partial \beta^{*}}{ }^{*}}, \text { fixed rotor speed mode }
\end{array}\right.
$$

\subsection{The Physical Interpretation of the Equivalent Droop Coefficient}

Using Equation (29), $K_{\mathrm{DFIG}}{ }^{*}$ can be simplified as:

$$
K_{\mathrm{DFIG}}^{*}=\frac{K_{d f^{*}}^{*}}{1-\frac{\Delta P_{\mathrm{ie}}^{*}}{\Delta P_{\mathrm{m}}^{*}}-\frac{\Delta P_{\mathrm{T} \omega}^{*}}{\Delta P_{\mathrm{m}}^{*}}}
$$

where

$$
\begin{aligned}
& \frac{\Delta P_{\mathrm{ie}}^{*}}{\Delta P_{\mathrm{m}}^{*}}=\left\{\begin{array}{l}
\frac{\omega_{0}^{*} K_{\mathrm{ie}}\left(T_{\mathrm{e}}-T_{\mathrm{p}}\right)}{P_{\partial \omega^{*}}}, \Delta \beta_{s}=0 \\
\frac{\frac{\omega_{0}{ }^{*} K_{\mathrm{ie}}}{K_{\mathrm{ip}}}}{P_{\partial \beta^{*}}}, \Delta \omega_{s}^{*}=0
\end{array}\right. \\
& \frac{\Delta P_{\mathrm{T} \omega}^{*}}{\Delta P_{\mathrm{m}}^{*}}=\left\{\begin{array}{l}
=\frac{P_{0}^{*}}{\omega_{0}^{*}} \\
P_{\partial \omega^{*}}{ }^{*} \\
0, \Delta \beta_{s}=0
\end{array}\right.
\end{aligned}
$$

According to Equation (7), the power variation is mainly composed of three parts: $\Delta P_{\text {droop }}{ }^{*}$ which means the power command of the droop control, $\Delta P_{\text {ie }}{ }^{*}$ which means the power variation caused by the integral term of torque variation, and $\Delta P_{\mathrm{T} \omega}{ }^{*}$ which means the power variation caused by the rotor speed variation multiplied by the initial torque. Considering the denominator of Equation (28), $\Delta P_{\text {ie }}$ ${ }^{*} / \Delta P_{\mathrm{m}}{ }^{*}$ and $\Delta P_{\mathrm{T} \omega}{ }^{*} / \Delta P_{\mathrm{m}}{ }^{*}$ represent the proportion of $\Delta P_{\mathrm{ie}}{ }^{*}$ and $\Delta P_{\mathrm{T} \omega}{ }^{*}$ in the change of the mechanical power of the DFIG.

According to Equation (31), $P_{0} * / \omega_{0} *$ represents the initial torque, which is the slope of the line between the initial operation point and the origin of the coordinate system in the diagram of the power 
and rotor speed. The denominator represents the ratio of the corresponding power change to the rotor speed change when the rotor speed changes slightly; that is, the slope of the tangent line at the initial operating point.

When the DFIG is running in the fixed-pitch angle mode, the initial operating point is on the right side of the MPP, the numerator is positive, the denominator is negative, and the speed is higher. When it is close to $\omega_{\mathrm{MPP}}$, the numerator is larger and the absolute value of the denominator is smaller, which tends to be negative infinity as a whole. Thus, the $K_{\text {DFIG }}$ tends to be 0 , which indicates that the DFIG is running at the MPP. The DFIG cannot participate in frequency regulation in this condition.

\section{Influencing Factors of Equivalent Droop Coefficient}

The equivalent droop coefficient derived in Section 3 is dependent on many factors, including the steady operating point and the control parameters of the DFIG model. It is necessary to study the key factors affecting the equivalent droop coefficient.

\subsection{Steady Operating Point}

Similar to conventional thermal power generators and hydraulic generators, a DFIG needs to reserve specific power to participate in PFR. Actual power absorbed from wind is less than the maximum available $P_{\mathrm{m}}$ by adjusting rotor speed and pitch angle, in other words. The $\left(\omega_{0}, \beta_{0}\right)$ represents the initial operating state of the DFIG. When the wind speed remains unchanged, the DFIG will operate at this point.

\subsubsection{Wind Speed $\left(V_{\mathrm{w}}\right)$}

The maximum available $P_{\mathrm{m}}$ of a DFIG is determined by the $V_{\mathrm{w}}$. Occurring at different wind speeds, the maximum $P_{\mathrm{m}}$ is different. When the DFIG runs following the specific $d$ scheduling instruction, the actual output power changes according to the real-time wind speed. During this study, the DFIG is operated either in a fixed pitch angle mode (Mode 1) or a fixed rotor speed mode (Mode 2). Power instruction can be determined at a certain wind speed. Also, $\omega_{0}$ and $\beta_{0}$ can be calculated. Above all, when the $d \%$ is fixed, the steady-state operation point is decided directly by the actual $V_{\mathrm{w}}$. Put differently, the $\omega_{0}$ and $\beta_{0}$ are determined by the $V_{\mathrm{w}}$.

Regarding a 1.5 MW WTG operating in a $50 \mathrm{~Hz}$ system, the relationship between the $V_{\mathrm{w}}$ and $K_{\text {DFIG }}$ is shown in Figure 4 with $d=10 \%, K_{\mathrm{ip}}=2.5, K_{\mathrm{ie}}=0.01, T_{\mathrm{e}}=10.1 \mathrm{~s}, T_{\mathrm{p}}=60.1 \mathrm{~s}$, and $K_{\mathrm{df}}=0.9 \mathrm{MW} / \mathrm{Hz}$ $\left(K_{\mathrm{df}}{ }^{*}=30\right)$. Other parameters are adopted as follows: $\rho=1.25 \mathrm{~kg} / \mathrm{m}^{3}, R=26.9147 \mathrm{~m}, G=27, p=3$, $f_{\mathrm{n}}=50 ; c_{1}=0.5176, c_{2}=116, c_{3}=0.4, c_{4}=5, c_{5}=21, c_{6}=0.0068, c_{7}=0.08, c_{8}=0.035$.

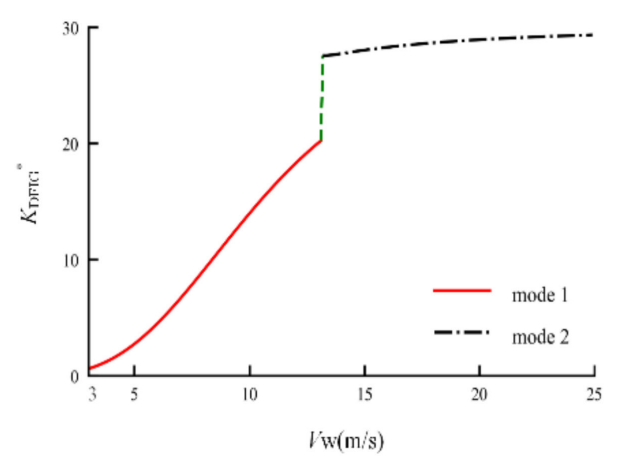

Figure 4. $K_{\mathrm{DFIG}}{ }^{*}$ with different wind speeds, the solid line for the fixed pitch angle mode (Mode 1 ), the dashed line for the fixed rotor speed mode (Mode 2).

Considering Figure 4 , the $V_{\mathrm{w}}=13.0 \mathrm{~m} / \mathrm{s}$ is a demarcation point of the two modes, where the $K_{\mathrm{DFIG}}$ * changes from 20.1 to 27.4. During the fixed-pitch angle mode (Mode 1), the DFIG participates in 
frequency regulation by adjusting the rotor speed. During the fixed rotor speed mode (Mode 2), the DFIG responds to the frequency change by changing the pitch angle.

\subsubsection{Load Shedding Ratio $(d)$}

The effect of the $d$ on the $K_{\text {DFIG }}$ is similar to that of wind speed on the $K_{\text {DFIG }}$. When the $V_{\mathrm{w}}$ is fixed, the steady-state operation point is determined by the actual $P_{\mathrm{m}}$, so the $\omega_{0}$ and $\beta_{0}$ are determined by the $d$. The relationship between the $d$ and $K_{\text {DFIG }}$ is shown in Figure 5, with the $d$ ranging from 0 to 0.20 .

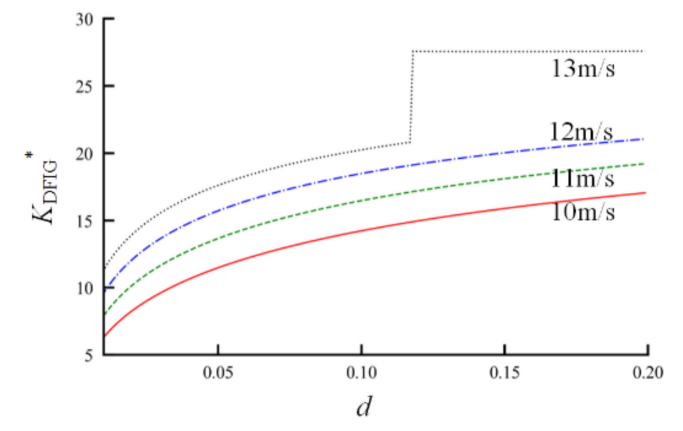

(a) Low $V_{\text {w }}$ scenarios

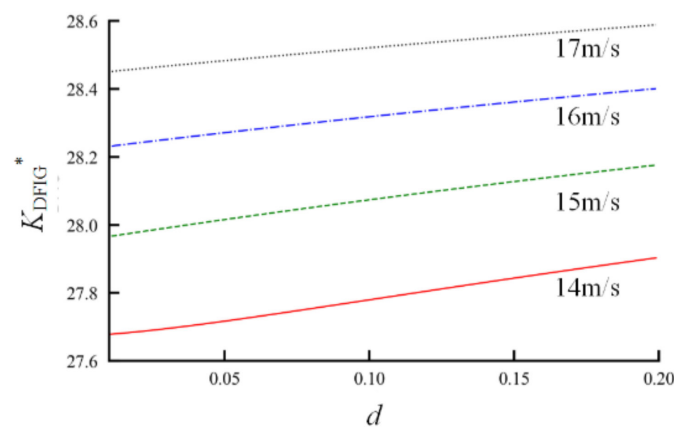

(b) High $V_{\mathrm{w}}$ scenarios

Figure 5. $K_{\mathrm{DFIG}}{ }^{*}$ with different load shedding ratios under different wind speeds, (a) for low wind speeds, (b) for high wind speeds.

Accompanying the increase in the load shedding ratio, the rotation reserve of the DFIG increases, which means that the power that the DFIG can use to participate in the frequency regulation increases. The higher the load shedding ratio, the greater the frequency regulation capacity of the DFIG at the same wind speed.

There is an apparent abrupt change on the curve with a wind speed of $13 \mathrm{~m} / \mathrm{s}$, which is caused by the switch of the DFIG frequency regulation mode. When the load shedding ratio is higher than 0.1172 , the mode of the DFIG frequency regulation is changed from adjusting the speed response frequency change to adjusting the pitch angle response frequency.

\subsection{Key Control Parameters}

Considering Equation (29), it can be concluded that the $K_{\mathrm{ie}}, K_{\mathrm{ip}}, T_{\mathrm{e}}, T_{\mathrm{p}}, K_{\mathrm{df}}$ are critical control parameters. The droop control coefficient $K_{\mathrm{df}}$ is the most important influencing actor. Concerning some cases, the $K_{\mathrm{DFIG}}$ can be regarded as the $K_{\mathrm{df}}$ multiplied by a coefficient when the key control parameters remain unchanged except the $K_{\mathrm{df}}$. The effect of the $K_{\mathrm{df}}$ on the $K_{\mathrm{DFIG}}$ is relatively clear. Therefore, the impact of the $T_{\mathrm{e}}, T_{\mathrm{p}}, K_{\mathrm{ie}}$, and $K_{\mathrm{ip}}$ on the DFIG PFR capability are discussed as follows.

\section{3. $T_{E}-T_{P}$}

$T_{\mathrm{e}}$ and $T_{\mathrm{p}}$ are the time delay of the reference rotor speed in the electrical and pitch angle models, respectively. During Mode 1 , the $K_{\mathrm{DFIG}}$ is related to $\left(T_{\mathrm{e}}-T_{\mathrm{p}}\right)$ directly from Equation (29). Inappropriate parameters may weaken the PFR capability of the DFIG.

Curves in Figure $6 \mathrm{a}$ are simulated low wind speeds, and Figure $6 \mathrm{~b}$ are simulated high wind speeds when $\left(T_{\mathrm{e}}-T_{\mathrm{p}}\right)$ ranges from $-1 \mathrm{~s}$ to $1 \mathrm{~s}$.

The simulation results show that $\left(T_{\mathrm{e}}-T_{\mathrm{p}}\right)$ has a significant effect on the $K_{\mathrm{DFIG}}$ in Mode 1 . The $T_{\mathrm{e}}$ and $T_{p}$ directly determine the response speed of the electrical control and pitch angle control. $\left(T_{e}-T_{p}\right)$ reflects the coordination between the electric power and the mechanical power control of the DFIG. A reasonable combination of the two parameters can effectively improve the PFR of the DFIG; on the contrary, an unreasonable combination may lead to the instability of the DFIG. 


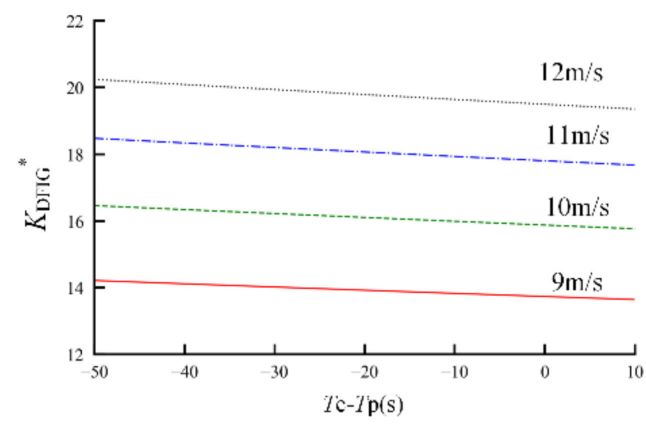

(a) Low $V_{\mathrm{w}}$ scenarios

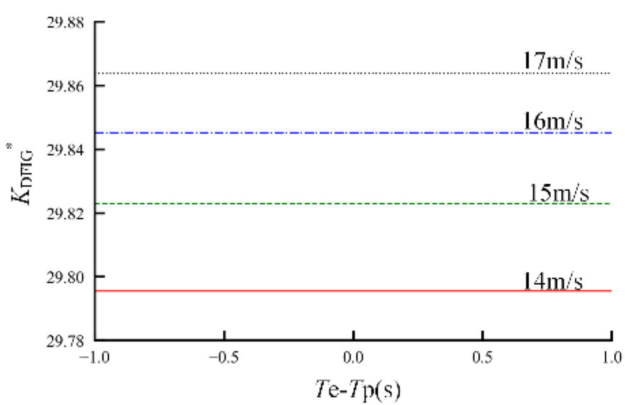

(b) High $V_{\mathrm{w}}$ scenarios

Figure 6. The $K_{\text {DFIG }}$ with different $\left(T_{\mathrm{e}}-T_{\mathrm{p}}\right)$ under different wind speeds, (a) for low wind speeds, (b) for high wind speeds.

\section{4. $K_{i e}$ and $K_{i p}$}

An integral block has a significant influence on the DFIG participating in the system PFR. Integral speed is determined by the integral coefficient. Tracking the performance of the rotor speed in the electrical and pitch angle models is affected directly by the integral coefficient, in other words. Therefore, the integral coefficient significantly affects the performance of the PFR. The effects of the $K_{\mathrm{ie}}$ and $K_{\mathrm{ip}}$ on $K_{\mathrm{DFIG}}{ }^{*}$ are shown in Figures 7 and 8.

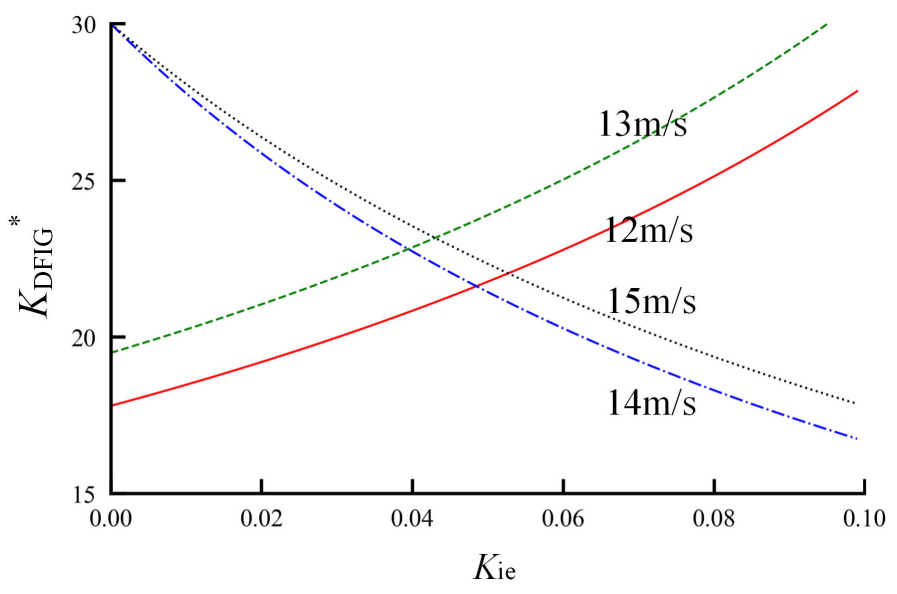

Figure 7. $K_{\text {DFIG }}$ with different Kie under different wind speeds.

Under low wind speeds, the DFIG operates in Mode 1, and the pitch angle holds. Thus, a variation of the $K_{\mathrm{ip}}$ in the pitch angle model has little effect on the PFR capability. That is to say, the $K_{\text {DFIG }}$ does not change with the $K_{\mathrm{ip}}$ in low $V_{\mathrm{w}}$. Accompanying the increase in the $K_{\mathrm{ie}}$, the $\omega_{\mathrm{ref}}^{\mathrm{e}}{ }^{*}$ reaches the $\omega_{\text {ref }}$ more quickly. Accordingly, rotor speed will reach the $\omega_{\text {ref }}$ more quickly. Under the same frequency offset, when the $K_{\text {ie }}$ is higher, the speed of releasing the PFR power is faster, and the $K_{\text {DFIG }}$ is greater. Therefore, the $K_{\text {DFIG }}$ grows with the $K_{\text {ie }}$ in low $V_{\mathrm{w}}$.

\subsection{Optimized Droop Control Coefficient}

Based on the above analysis and derivation, the DFIG can be made to have a relatively stable frequency regulation ability similar to that of thermal power units. Through parameter adjustment, the DFIG can meet the grid frequency regulation requirements if the DFIG is expected to have a constant

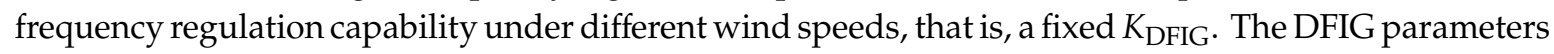
need to be adjusted in real-time according to wind speed, which is unrealistic. Therefore, the frequency 
regulation capability of the DFIG is allowed to fluctuate within a specific range. The adjustment coefficient of conventional thermal power generators is generally set as $3 \sim 5 \%$, and the acceptable $K_{\mathrm{DFIG}}$ range is $20.00 \sim 33.33$.

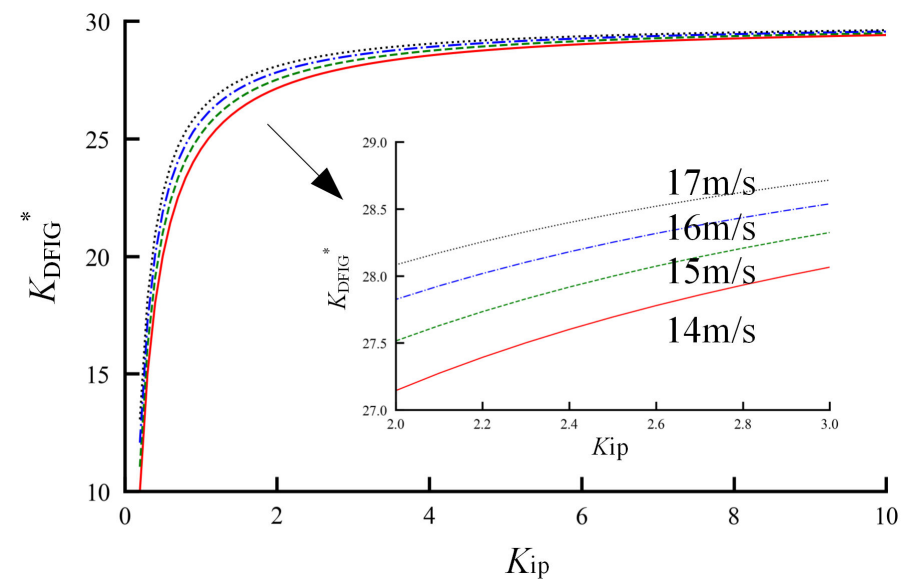

Figure 8. $K_{\text {DFIG }}$ with different $K_{\text {ip }}$ under different wind speeds.

The realization of parameter adjustment in practical engineering is difficult and uneconomical. Therefore, as few parameters are adjusted as possible, and the droop coefficient $K_{\mathrm{df}}$, which has a clear relationship with the frequency regulation capability, is selected as the adjustment parameter in this paper. The $K_{\text {DFIG }}$ with an optimized droop coefficient under different wind speed is shown in Figure 9, and the value of the optimized droop coefficient is shown in Table 1.

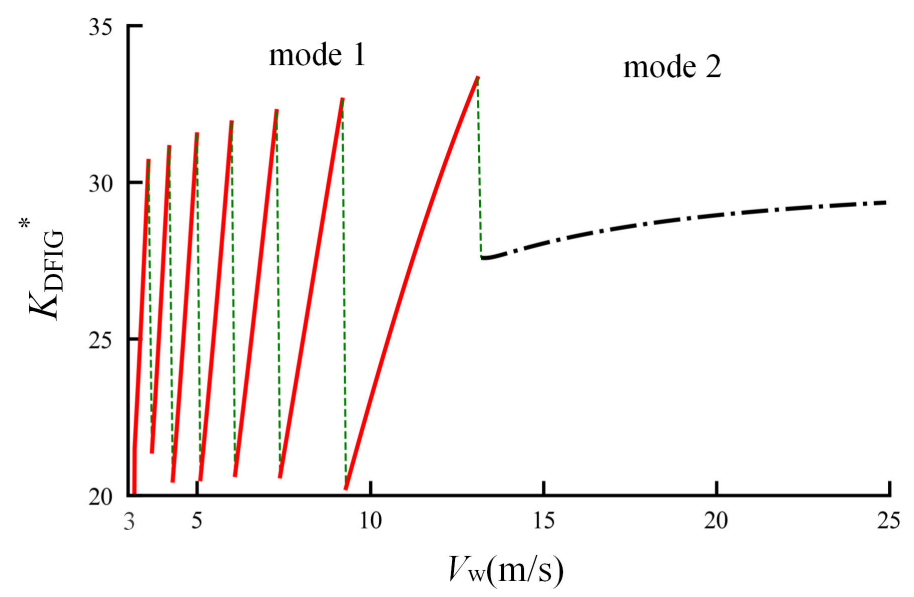

Figure 9. The $K_{\mathrm{DFIG}}$ under different wind speeds with a fixed $K_{\mathrm{df}}$, the solid lines for the fixed pitch angle mode (Mode 1), the dashed line for the fixed rotor speed mode (Mode 2).

Table 1. The optimized droop coefficient under different wind speeds, brackets for containing upper or lower limit, parentheses for excluding upper or lower limit.

\begin{tabular}{ccc}
\hline$V_{\mathbf{m}}(\mathbf{m} / \mathbf{s})$ & $\boldsymbol{K}_{\mathbf{d f}}$ & $\boldsymbol{K}_{\text {DFIG }}{ }^{*}$ \\
\hline$(3.0,3.6]$ & 872 & $(21.51,33.30]$ \\
$(3.6,4.2]$ & 560.5 & $(21.40,33.32]$ \\
$(4.2,5.0]$ & 344.3 & $(20.47,33.32]$ \\
$(5.0,6.0]$ & 212.0 & $(20.52,33.32]$ \\
$(6.0,7.3]$ & 131.4 & $(20.65,33.31]$ \\
$(7.3,9.2]$ & 81.3 & $(20.61,33.30]$ \\
$(9.2,13.0]$ & 49.4 & $(20.23,33.32]$ \\
$(13.0,25.0)$ & 30 & $(27.58,29.36)$ \\
\hline
\end{tabular}




\section{Case Studies}

Regarding the 1.5 MW wind turbine generator used in the previous sections, its PFR capability is verified in this section with wind speed data from NASA [26]. All wind data are for a wind speed at $50 \mathrm{~m}$ in the selected area.

\subsection{Cases to Verify the Proposed Method}

To verify the proposed PFR evaluation method, two models are adopted in this section: an IEEE 9-bus model and an equivalent provincial model of China with 140 buses. Regarding the IEEE 9-bus model, the total load is $315 \mathrm{MW}$, and the total installed generation capacity is $567 \mathrm{MVA}$. The synchronous generator at bus 3 is replaced with 85 DFIGs to keep generator capacity, and the installed capacity of each DFIG is 1.5 MVA. Therefore, the proportion of DFIGs is about $22.5 \%$ in the 9-bus model. Concerning the provincial model of China, the total load is $58.876 \mathrm{GW}$, the installed capacity of conventional generators is $69.008 \mathrm{GW}$, and the installed capacity of the DFIGs is $9.24 \mathrm{GW}$. Therefore, the proportion of DFIGs is about $13.39 \%$ in the provincial model of China.

Regarding the IEEE 9-bus model, the system frequency and active power of the DFIGs are shown in Figure 10 for an event of a shedding generator at bus 1 by $10 \%$ at $1 \mathrm{~s}$, essentially, the loss of active power is $23 \mathrm{MW}$.

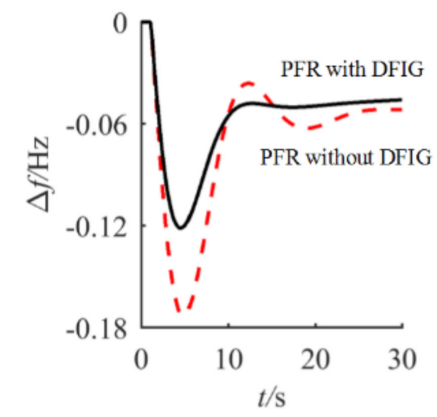

(a) frequency

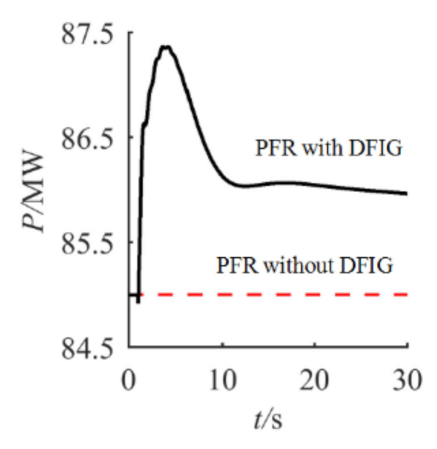

(b) active power of DFIGs

Figure 10. Simulation results with a loss of $23 \mathrm{MW}$ generation, (a) for system frequency, (b) for active power of DFIGs.

When the DFIG does not participate in frequency regulation, the variation of the system steady-state frequency is $0.055 \mathrm{~Hz}$. When the DFIG participates in frequency regulation, the variation of the system steady-state frequency is $0.045 \mathrm{~Hz}$, and the steady-state output increment of the DFIGs is $0.947 \mathrm{MW}$. According to simulation data, the $K_{\mathrm{DFIG}}{ }^{*}$ is $94.70 \mathrm{MW} / \mathrm{Hz}$, close to the theoretical value calculated using Equation (29), i.e., $96.58 \mathrm{MW} / \mathrm{Hz}$.

Regarding the provincial model of China, the system frequency and active power of the DFIGs are shown in Figure 11 for an event of shedding a synchronous generator at bus 143 by $10 \%$ at $1 \mathrm{~s}$, essentially, the loss of active power is $66 \mathrm{MW}$.

When the DFIG does not participate in frequency regulation, the variation of the system steady-state frequency is $3.02 \mathrm{mHz}$, and the maximum frequency deviation is $6.49 \mathrm{mHz}$. When the DFIG participates in frequency regulation, the variation of the system steady-state frequency is $2.64 \mathrm{mHz}$, the maximum frequency deviation is $5.05 \mathrm{mHz}$, and the steady-state output increment of the DFIGs is $8.60 \mathrm{MW}$. The $K_{\text {DFIG }}{ }^{*}$ of the DFIG is 17.64 (3259.5849 MW/Hz).

When the load at bus 81 is shed by $10 \%$ at $1 \mathrm{~s}$ with a load loss of $94 \mathrm{MW}$, the system frequency and active power of the DFIGs in the provincial model of China are shown in Figure 12. 


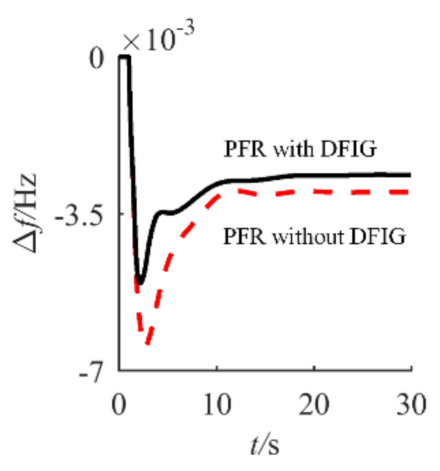

(a) frequency

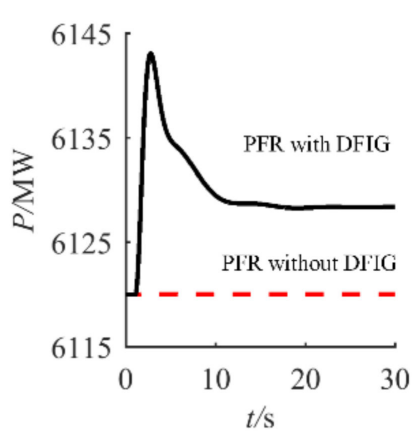

(b) active power of DFIGs

Figure 11. Simulation results with a loss of $66 \mathrm{MW}$ generation, (a) for the system frequency, (b) for the active power of the DFIGs.

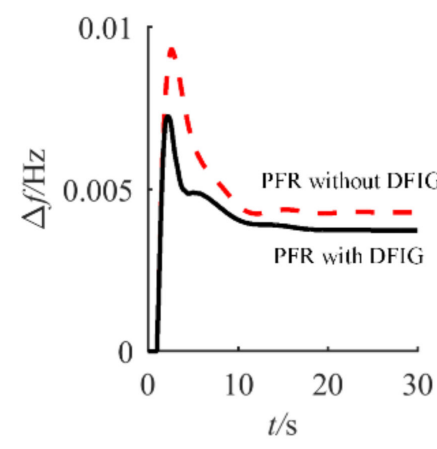

(a) system frequency

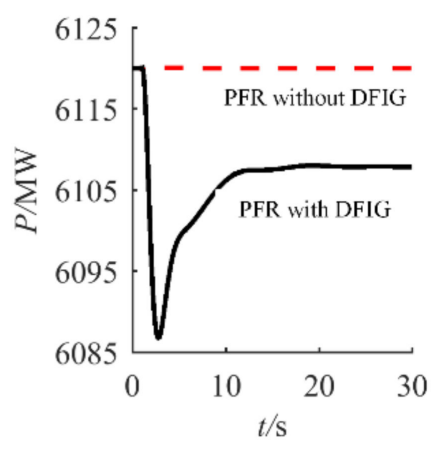

(b) active power of DFIGs

Figure 12. Simulation results with a loss of a $94 \mathrm{MW}$ load, (a) for the system frequency, (b) for the active power of the DFIGs.

When the DFIG participates in frequency regulation, the variation of the system steady-state frequency is $3.75 \mathrm{mHz}$, the maximum frequency deviation is $5.05 \mathrm{mHz}$, and the steady-state output increment of the DFIGs is $12.23 \mathrm{MW}$. According to simulation data, the $K_{\mathrm{DFIG}}{ }^{*}$ is 17.63 or $3258.663 \mathrm{MW} / \mathrm{Hz}$. The $K_{\text {DFIG }}{ }^{*}$ of the DFIG calculated using Equation (24) is 18.02 or $3329.893 \mathrm{MW} / \mathrm{Hz}$. The main reason why the latter is slightly larger is that the second-order term is omitted in Equation (16).

Many cases are studied to verify the proposed method, and the results are shown in Figure 13. The solid line is the $K_{\mathrm{DFIG}}{ }^{*}$, calculated from the equation, and the scatters are the $K_{\mathrm{DFIG}}{ }^{*}$ calculated from simulation data. The simulation results show that when the variation of frequency is in the range of $-0.04 \sim 0.04 \mathrm{~Hz}$, the error of the $K_{\mathrm{DFIG}}{ }^{*}$ calculated from the equation is less than $5 \%$.

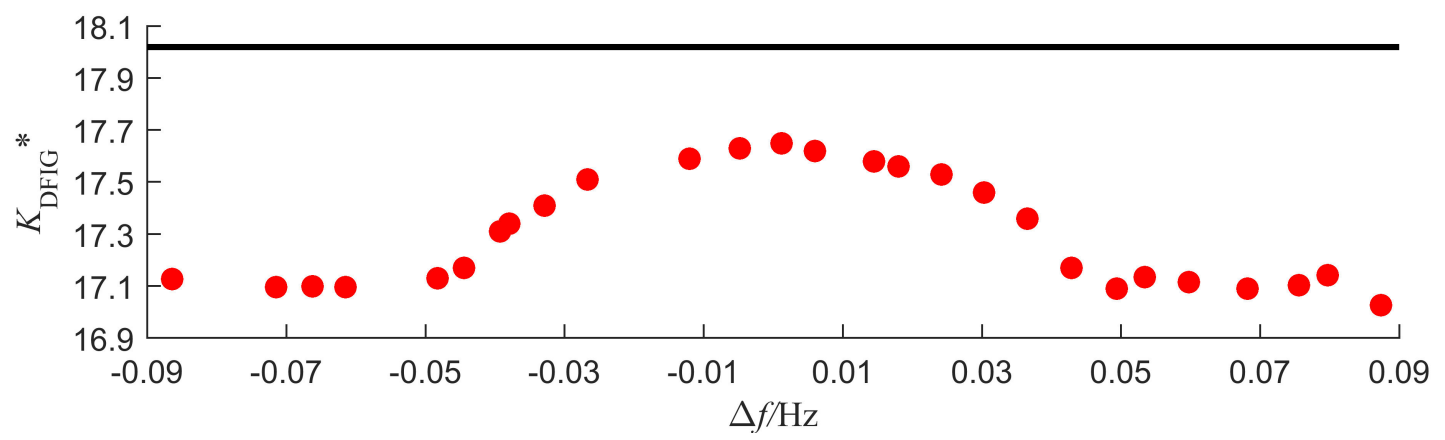

Figure 13. Theoretical and simulated $K_{\mathrm{DFIG}}{ }^{*}$ under different events, the solid line for the $K_{\mathrm{DFIG}}{ }^{*}$ calculated from an equation, the dots for the $K_{\mathrm{DFIG}}{ }^{*}$ calculated from simulation. 


\subsection{PFR Capability with Wind Fluctuation}

\subsection{1. $K_{\mathrm{DFIG}}{ }^{*}$ of Single DFIG under Field Wind Speed}

Here, a DFIG is analyzed with wind speed data taken from a city in Shandong, China, with a sample resolution of one day. The wind speed for a year is shown in Figure 13. The equivalent PFR droop coefficient of the DFIG is calculated and shown in Figure 14.

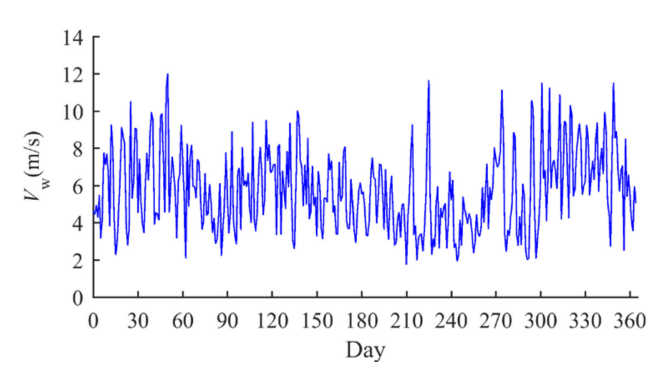

(a) Wind speed

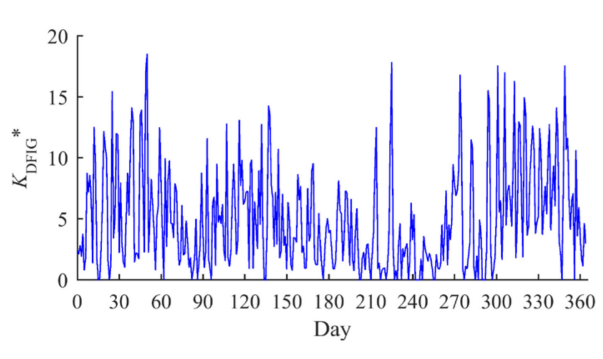

(b) Equivalent PFR droop coefficient

Figure 14. Wind speed and the $K_{\mathrm{DFIG}}{ }^{*}$ of a city for a year, the wind speeds data is taken from NASA [26].

Since the DFIG is set to cut in when $V_{\mathrm{W}}>3 \mathrm{~m} / \mathrm{s}$ and to cut out when $V_{\mathrm{W}}>25 \mathrm{~m} / \mathrm{s}$, there are several points in Figure 14 where the $K_{\text {DFIG }}=0$, which indicates that the DFIG stops working when the $V_{\mathrm{W}}<3 \mathrm{~m} / \mathrm{s}$. Concerning other wind speeds, the PFR capability is greatly affected by wind speed. The $K_{\text {DFIG }}{ }^{*}$ ranges from 0.7401 to 18.5158 in this example. Its mean value is 5.4880 , and the standard deviation is 17.3162 .

\subsubsection{Aggregated $K_{\mathrm{DFIG}}{ }^{*}$ of DFIGs in a Province}

Take eight large wind power plants from Shandong Province as an example. The installed DFIG capacity and actual wind speed in a year are shown in Table 2 and Figure 15. The equivalent PFR droop coefficient of these wind farms is shown in Figure 16.

Here in this example, the total $K_{\mathrm{DFIG}}{ }^{*}$ values range from 0.1503 to 17.2113 . Its mean value is 4.803, and its standard deviation is 13.4912. Compared with the result in Figure 14, the mean value of the $K_{\mathrm{DFIG}}$ * in Figure 16 is less, but the standard deviation also is reduced. Put differently, with more wind farms participating in the PFR, the equivalent PFR capability of all wind farms becomes more stable.

Table 2. Installed capacity and location of some wind farms in Shandong Province.

\begin{tabular}{cccc}
\hline Wind Farm(City) & Latitude & Longitude & Installed Capacity \\
\hline A(Dongying) & $37.55^{\circ} \mathrm{N}$ & $118.53^{\circ} \mathrm{E}$ & $150 \mathrm{MW}$ \\
B(Penglai) & $37.80^{\circ} \mathrm{N}$ & $120.81^{\circ} \mathrm{E}$ & $150 \mathrm{MW}$ \\
$\mathrm{C}($ Weihai) & $37.49^{\circ} \mathrm{N}$ & $122.11^{\circ} \mathrm{E}$ & $200 \mathrm{MW}$ \\
$\mathrm{D}($ Yantai) & $37.52^{\circ} \mathrm{N}$ & $121.42^{\circ} \mathrm{E}$ & $200 \mathrm{MW}$ \\
E(Jinan) & $36.66^{\circ} \mathrm{N}$ & $117.01^{\circ} \mathrm{E}$ & $300 \mathrm{MW}$ \\
F(Weifang) & $36.71^{\circ} \mathrm{N}$ & $119.09^{\circ} \mathrm{E}$ & $200 \mathrm{MW}$ \\
G(Rizhao) & $35.43^{\circ} \mathrm{N}$ & $119.48^{\circ} \mathrm{E}$ & $100 \mathrm{MW}$ \\
H(Zibo) & $36.79^{\circ} \mathrm{N}$ & $118.12^{\circ} \mathrm{E}$ & $200 \mathrm{MW}$ \\
\hline
\end{tabular}



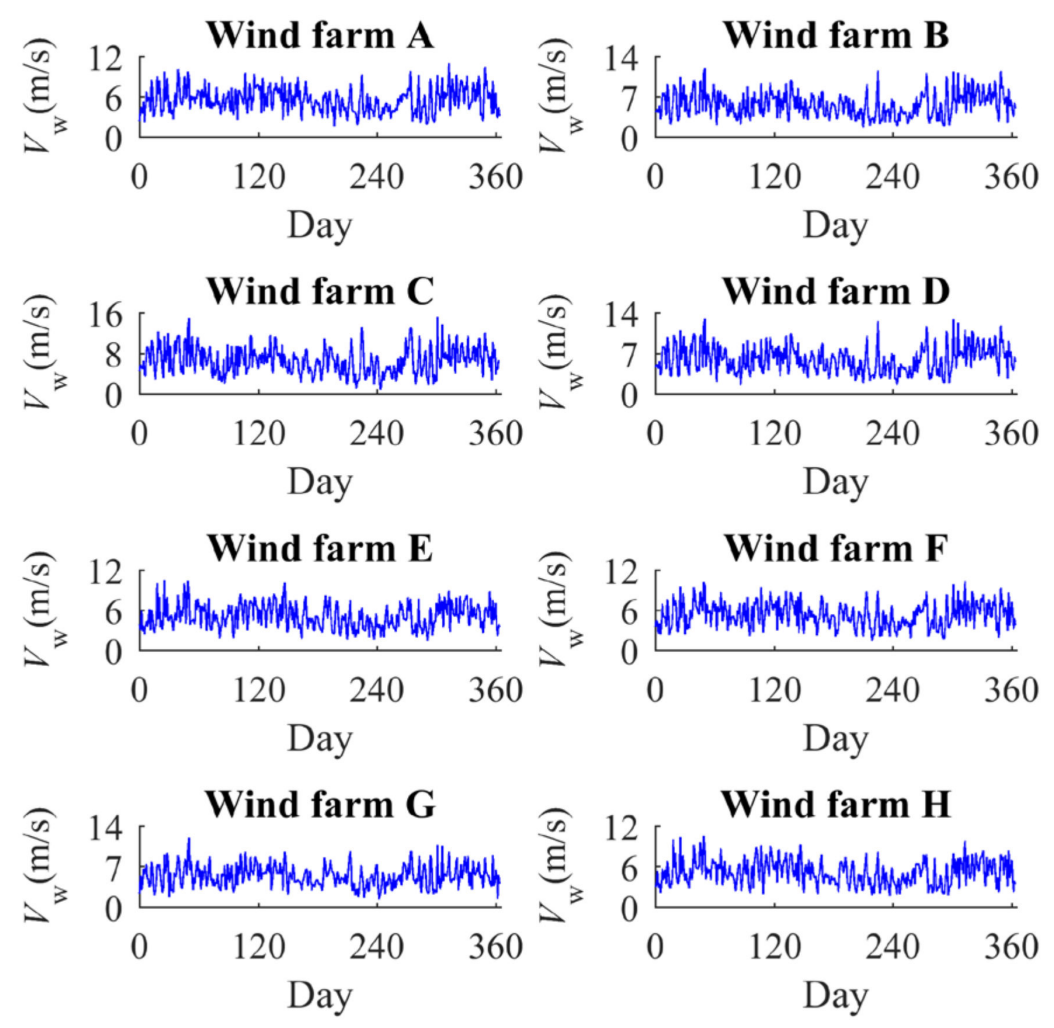

Figure 15. Wind speeds of wind farms from Shandong Province for a year, data taken from NASA [26].

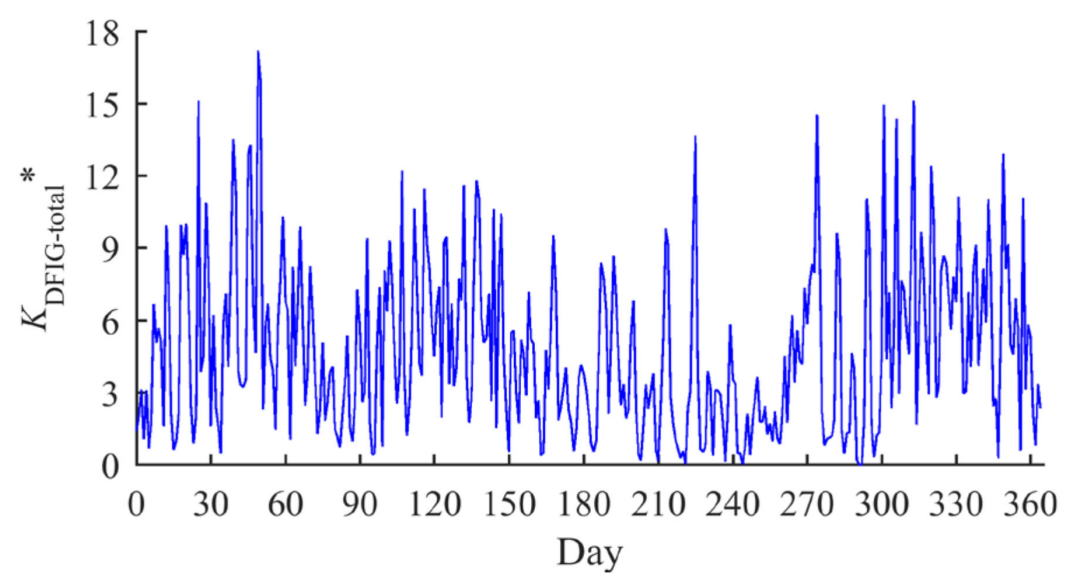

Figure 16. Aggregated $K_{\mathrm{DFIG}}{ }^{*}$ of all wind farms in Shandong Province for a year, fluctuated significantly with the changing wind speed.

Though the standard deviation of the $K_{\mathrm{DFIG}}{ }^{*}$ in Figure 16 is reduced, the total $K_{\mathrm{DFIG}}{ }^{*}$ still fluctuates significantly with the changing wind speed. To make the PFR capability more stable, the droop coefficient of all DFIGs in the province can be adjusted with the parameters in Table 1. The PFR capability of the whole province for a year with an optimized droop coefficient is calculated and shown in Figure 17.

It can be seen from Figure 17 that, with the optimized droop coefficient, $K_{\text {DFIG-total }}{ }^{*}$ ranges from 1.7855 to 30.1413 . Its mean value is 24.0400 , and the standard deviation reduces to 5.1176 . The method of adjusting parameters makes the frequency regulation capability of wind farms in the province guaranteed. Therefore, the PFR capability can be guaranteed if the $K_{\mathrm{df}}$ can be dynamically adjusted. 


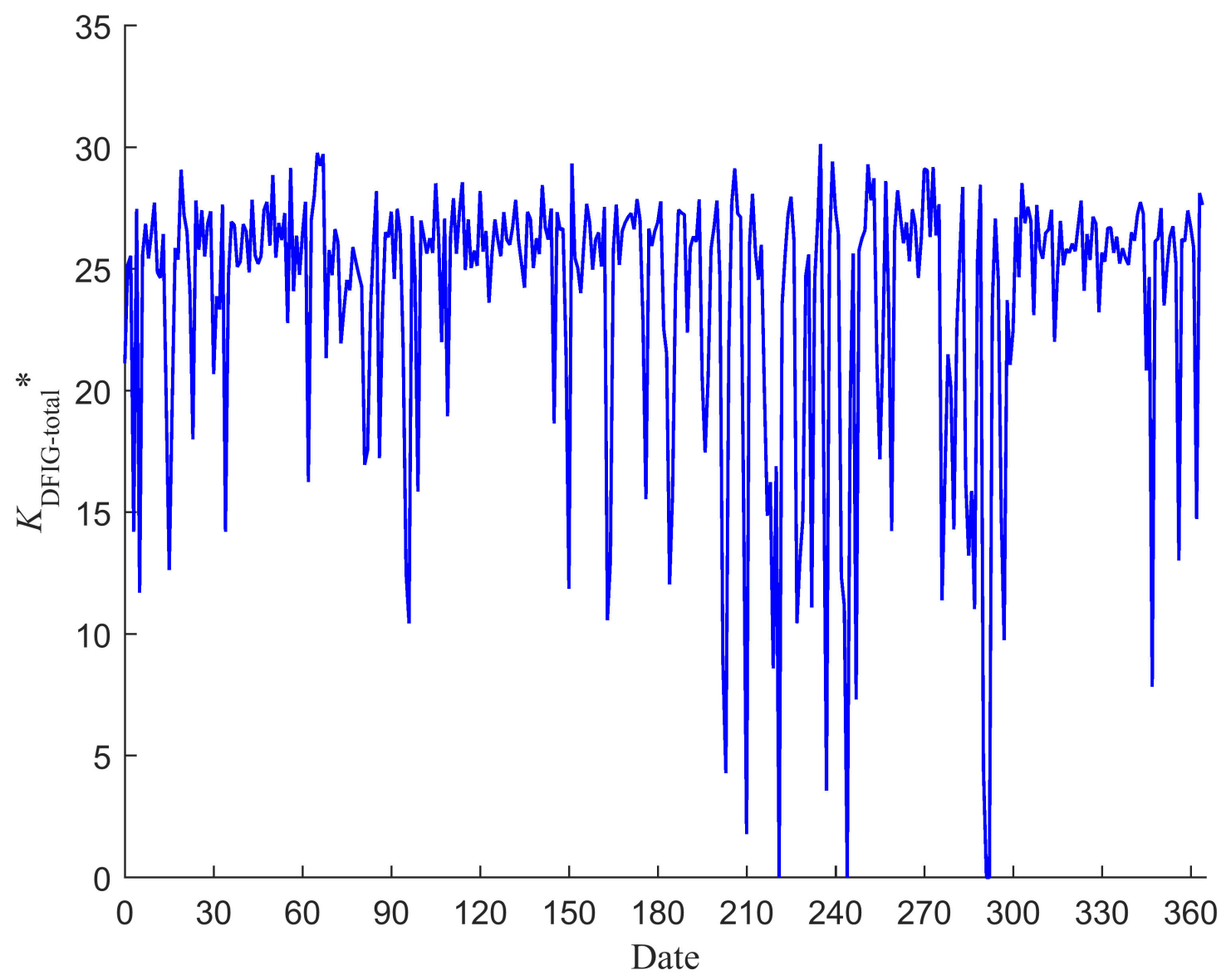

Figure 17. The $K_{\text {DFIG-total }}$ * for a year with an optimized droop coefficient fluctuating slightly with the changing wind speed.

\section{Conclusions}

Accompanying more and more DFIGs integrated into power systems, DFIGs are required to participate in PFR. To evaluate the DFIG's PFR capability, this paper proposed a method to estimate the DFIG's equivalent droop coefficient. The derived equivalent droop coefficient can be used to readily estimate the contribution of the DFIG to the system PFR. The equivalent droop coefficient is dependent on many factors, including a steady operating point and the control parameters of the DFIG model. When control parameters are fixed, the DFIG's PFR capability is greatly affected by wind speed. The PFR capability of the DFIG can be guaranteed if the droop coefficient can be dynamically adjusted for different wind speed ranges.

Author Contributions: Conceptualization, C.L.; Funding acquisition, H.Z.; Resources, Q.G. and Y.Z.; Validation, Z.H.; Writing-review \& editing, V.T. All authors have read and agreed to the published version of the manuscript.

Funding: This research was funded by the State Key Laboratory of HVDC, Electric Power Research Institute, China Southern Power Grid (No: SKLHVDC-2019-KF-15) and Young Scholars Program of Shandong University (No: 2018WLJH31).

Conflicts of Interest: The authors declare no conflict of interest.

\section{References}

1. Ding, L.; Yin, S.; Wang, T.X.; Jiang, J.; Cheng, F. Integrated Frequency Control Strategy of DFIGs Based on Virtual Inertia and Over-Speed Control Power System Technology. Power Syst. Technol. 2015, 39, $2385-2391$.

2. Chen, K.; Peng, P.Q.; Li, H.R.; Xu, T.Y.; Li, C.G. DFIG Primary Frequency Regulation Strategy with Optimal Dynamic Droop Control under Variable Wind Speeds. IOP Conf. Ser. Earth Environ. Sci. 2018, 188, 012087. [CrossRef] 
3. Cheng, Y.; Azizipanah-Abarghooee, R.; Azizi, S.; Ding, L.; Terzija, V. Smart Frequency Control in Low Inertia Energy Systems Based on Frequency Response Techniques: A review. Appl. Energy 2020, 279, 115798. [CrossRef]

4. Li, C.; Wu, Y.; Sun, Y.; Zhang, H.; Liu, Y.; Liu, Y.; Terzija, V. Continuous Under-Frequency Load Shedding for Power System Adaptive Frequency Control. IEEE Trans. Power Syst. 2020, 35, 950-961. [CrossRef]

5. Mehta, B.; Bhatt, P.; Pandya, V. Small Signal Stability Analysis of Power Systems with DFIG Based Wind Power Penetration. Int. J. Electr. Power Energy Syst. 2014, 58, 64-74. [CrossRef]

6. Tian, X.; Wang, W.; Chi, Y.; Li, Y.; Liu, C. Adaptation Virtual Inertia Control Strategy of DFIG and Assessment of Equivalent Virtual Inertia Time Constant of Connected Power System. J. Eng. 2017, 2017, 922-928. [CrossRef]

7. Li, S.; Deng, C.; Shu, Z.; Huang, W.; He, J.; You, Z. Equivalent Inertial Time Constant of Doubly Fed Induction Generator Considering Synthetic Inertial Control. J. Renew. Sustain. Energy 2016, 8, 053304. [CrossRef]

8. Arani, M.F.M.; Mohamed, Y.A.-R.I. Dynamic Droop Control for Wind Turbines Participating in Primary Frequency Regulation in Microgrids. IEEE Trans. Smart Grid 2018, 9, 5742-5751. [CrossRef]

9. Vidyanandan, K.V.; Senroy, N. Closure to Discussion on "Primary Frequency Regulation by Deloaded Wind Turbines Using Variable Droop". IEEE Trans. Power Syst. 2014, 29, 414-415. [CrossRef]

10. De Almeida, R.G.; Lopes, J.A.P. Participation of Doubly Fed Induction Wind Generators in System Frequency Regulation. IEEE Transactions on Power Syst. 2007, 22, 944-950. [CrossRef]

11. Zhang, Z.; Sun, Y.; Li, G.; Cheng, L.; Lin, J. Frequency Regulation by Doubly Fed Induction Generator Wind Turbines Based on Coordinated Over-Speed Control and Pitch Control. Autom. Electr. Power Syst. 2011, 35, 20-25.

12. Mahvash, H.; Taher, S.A.; Rahimi, M.; Shahidehpour, M. Enhancement of DFIG Performance at High Wind Speed Using Fractional Order PI Controller in Pitch Compensation loop. Int. J. Electr. Power Energy Syst. 2019, 104, 259-268. [CrossRef]

13. Yuan, X.; Li, Y. Control of Variable Pitch and Variable Speed Direct-Drive Wind Turbines in Weak Grid Systems with Active Power Balance. IET Renew. Power Gener. 2014, 8, 119-131. [CrossRef]

14. Wu, F.; Zhang, X.-P.; Godfrey, K.; Ju, P. Small Signal Stability Analysis and Optimal Control of A Wind Turbine with Doubly Fed Induction Generator. IET Gener. Transm. Distrib. 2007, 1, 751-760. [CrossRef]

15. Vidyanandan, K.V.; Senroy, N. Primary Frequency Regulation by De-Loaded Wind Turbines Using Variable Droop. IEEE Trans. Power Syst. 2013, 28, 837-846. [CrossRef]

16. Yang, J.-S.; Chen, Y.-W.; Hsu, Y.-Y. Small-Signal Stability Analysis and Particle Swarm Optimisation Self-Tuning Frequency Control for An Islanding System with DFIG Wind Farm. IET Gener. Transm. Distrib. 2019, 13, 563-574. [CrossRef]

17. Attya, A.B.; Hartkopf, T. Penetration Impact of Wind Farms Equipped with Frequency Variations Ride Through Algorithm on Power System Frequency Response. Int. J. Electr. Power Energy Syst. 2012, 40, 94-103. [CrossRef]

18. Ramos, C.J.; Martins, A.P.; Carvalho, A.D.S. Power System Frequency Estimation Using A Least Mean Squares Differentiator. Int. J. Electr. Power Energy Syst. 2017, 87, 166-175. [CrossRef]

19. Jiang, W.; Lu, J. Frequency Estimation in Wind Farm Integrated Systems Using Artificial Neural Network. Int. J. Electr. Power Energy Syst. 2014, 62, 72-79. [CrossRef]

20. Polajžer, B.; Dolinar, D.; Ritonja, J. Estimation of Area's Frequency Response Characteristic During Large Frequency Changes Using Local Correlation. IEEE Trans. Power Syst. 2016, 31, 3160-3168. [CrossRef]

21. Lam, A.Y.S.; Leung, K.-C.; Li, V.O.K. Capacity Estimation for Vehicle-to-Grid Frequency Regulation Services with Smart Charging Mechanism. IEEE Trans. Smart Grid 2016, 7, 156-166. [CrossRef]

22. Sun, D.; Sun, L.; Wu, F.; Zu, G. Frequency Inertia Response Control of SCESS-DFIG under Fluctuating Wind Speeds Based on Extended State Observers. Energies 2018, 11, 830. [CrossRef]

23. Yan, X.; Song, Z.; Xu, Y.; Sun, Y.; Wang, Z.; Sun, X. Study of Inertia and Damping Characteristics of Doubly Fed Induction Generators and Improved Additional Frequency Control Strategy. Energies 2018, 12, 38. [CrossRef]

24. Abad, G.; López, J.; Rodríguez, M.A.; Marroyo, L.; Iwanski, G. Doubly Fed Induction Machine: Modeling and Control for Wind Energy Generation; John Wiley \& Sons, Inc.: Hoboken, NJ, USA, 2011. 
25. Zhang, S.; Mishra, Y.; Yuan, B.; Zhao, J.; Shahidehpour, M. Primary Frequency Controller with Prediction-Based Droop Coefficient for Wind-Storage Systems Under Spot Market Rules. Energies 2018, 11, 2340. [CrossRef]

26. NASA Power Data Access Viewer. Available online: https://power.larc.nasa.gov/data-access-viewer/ (accessed on 10 September 2020).

Publisher's Note: MDPI stays neutral with regard to jurisdictional claims in published maps and institutional affiliations.

(C) 2020 by the authors. Licensee MDPI, Basel, Switzerland. This article is an open access article distributed under the terms and conditions of the Creative Commons Attribution (CC BY) license (http://creativecommons.org/licenses/by/4.0/). 